\title{
Friedman Rule in a Model with Endogenous Growth and Cash-in-advance Constraint
}

\author{
FIROUZ GAHVARI
}

CESIFO WORKING PAPER No. 2708

CATEgORY 1: Public FinANCE

JULY 2009

\footnotetext{
An electronic version of the paper may be downloaded

- from the SSRN website: www.SSRN.com

- from the RePEc website: - from the CESifo website: 


\title{
Friedman Rule in a Model with Endogenous Growth and Cash-in-advance Constraint
}

\begin{abstract}
This paper introduces money into an overlapping generations model with endogenous growth. The model, due to Docquier et al. (2007), exhibits a positive intergenerational externality which precludes its laissez-fair equilibrium to be optimal even if the government can control the level of physical capital and set it to satisfy the modified golden rule. The main message of the paper is that, as long as the modified golden rule is attained, Friedman rule is optimal. The result holds regardless of the ability of the government to internalize the externality and control the level of human capital. Other results include: (i) violation of Friedman rule for a different second-best environment wherein human capital accumulation is controlled but not physical capital accumulation; (ii) existence of a negative relationship between money growth rate and the economy's endogenous growth rate, and (iii) non-uniqueness of Friedman rule.
\end{abstract}

JEL Code: H21, H52.

Keywords: Friedman rule, endogenous growth, investment in human capital, overlapping generations, second best.

\author{
Firouz Gahvari \\ Department of Economics \\ University of Illinois at Urbana-Champaign \\ USA - Urbana, IL 61801 \\ fgahvari@illinois.edu
}

June 2009 


\section{Introduction}

For over four decades, the optimal money supply literature has studied the environments under which the Friedman rule may or may not hold. One interesting result, in the context of overlapping-generations models à la Diamond (1965), is the importance of attaining the (modified) golden rule for the application of Friedman rule. Weiss (1980) had originally argued that Friedman rule does not hold in overlapping generations models. Later, Able (1987) and Gahvari (1988) showed that Weiss's result was due to the generic failure of the laissez-faire equilibrium of overlapping generations models to deliver the (modified) golden rule. Introducing generational lump-sum tax and transfers, or a debt policy, to control capital accumulation allows the economy to attain the (modified) golden rule and restores the optimality of Friedman rule. ${ }^{1}$

One important feature of Diamond's (1965) model is that it turns it into a first-best environment through the control of economy's physical capital: The model contains no other intrinsic sources of market failures (such as externalities). Extending the model to include some form of market failure destroys this particular feature of Diamond's model. This opens up the question of optimality of Friedman rule even if the (modified) golden rule is attained. van der Ploeg and Alogoskoufis (1994), for example, demonstrate that Friedman rule is violated in an overlapping generations model that exhibits endogenous growth. ${ }^{2}$ However, although van der Ploeg and Alogoskoufis allow for lump-sum taxation and debt policy, they do not set the fiscal instruments in such a way as to fully control the capital stock of the economy. Indeed, in their model, it is the non-neutrality

\footnotetext{
${ }^{1}$ Gahvari (1988) went further and showed that the optimality of Friedman rule does not rest on the attainment of the modified golden rule. If a switch to Friedman rule is accompanied by generation specific lump-sum taxes that neutralize the ensuing intergenerational wealth transfers, Friedman rule becomes optimal given any initial steady state laissez faire equilibrium. This finding, and the importance of intergenerational wealth transfers appear to have gone unnoticed in the subsequent literature dealing with the Friedman rule until its rediscovery by Bhattacharya et al. (2005). See, e.g., Freeman (1993), and Smith (1991, 2002). An exception is Ireland (2005); this issue has been discussed in Gahvari (2007).

${ }^{2}$ They consider a setup as in Weil (1989) wherein individuals are infinitely-lived but that new generations are born every period. They also rationalize money by putting real balances in the utility function.
} 
of monetary policy that leads to the breakdown of Friedman rule.

Two questions arise regarding the optimality of Friedman rule when physical capital is fully controlled. One concerns an environment wherein the government has additional fiscal instruments to offset the other sources of distortion in the economy. The second environment allows for no additional instruments. The latter environment is particularly interesting in light of Phelps (1973) who raised one of the earliest objections to Friedman rule. Phelps' argument relied on an application of the general theory of second best; see Lipsey and Lancaster (1956). This well-known proposition in public finance teaches us that familiar first-best prescriptions often do not hold in second-best environments. Put differently, if there already exists a distortion in the economy, adding another source of distortion can enhance welfare. Applied to a monetary economy, the lesson is that the violation of Friedman rule may in fact be welfare increasing in a second-best environment.

The current paper addresses both of these questions and studies if the control of physical capital ensures the optimality of Friedman rule in overlapping generations model that exhibit an inherent source of distortion-with and without correcting the distortion. The model that I use for this purpose is due to Docquier et al. (2007) who have recently extended Diamond's model to allow for endogenous growth that emanates from building up one's human capital. This model is interesting not only because it allows for (per capita) growth that does not exist in Diamond (1965), but also the fact that its laissez-faire equilibrium exhibits an additional source of market failure through an intergenerational externality. The externality is due to the positive effect of investment in education on the human capital of not just the investor, but his children as well. It arises when one's human capital is determined partly through education and partly through the human capital one inherits from his parents. However, in deciding how much to spend on education, individuals ignore the effect that their decision has on the human capital of their children. 
To address these questions, the paper introduces money in Docquier et al.'s (2007) model and rationalize it through a cash-in-advance constraint. ${ }^{3}$ It derives the dynamics of the model and characterize its balanced growth path under laissez faire. Subsequently, it derives the first-best allocations of this economy and shows that they are not affected by the introduction of money. ${ }^{4}$ It proves that the implementation of the first-best, i.e. when both physical and human capital are fully controlled, requires Friedman rule to be satisfied. This result generalizes the earlier result of Able (1987) and Gahvari (1988) to overlapping generations models with endogenous growth. It also puts van der Ploeg and Alogoskoufis' result to the contrary in the right perspective.

Subsequently, the paper proves that Friedman rule holds even if one cannot control human capital accumulation and internalize the externality of education. On the face of it, this result appears to be surprising in the light of Phelps (1973) and the second-best logic. The key to understanding it is that introducing another distortion in the economy via the violation of Friedman rule does nothing to alleviate the existing distortion in human capital accumulation, as long as one fully controls the economy's stock of physical capital. The paper highlights this point.

Other grounds covered by this paper include: (i) A comparison between the values that other economic variables (besides the nominal interest rate) assume in the first- and second-best environments studied. Whereas the value of the nominal interest rate is zero in both environments, the second-best entails a lower endogenous rate of growth and a lower monetary growth rate. (ii) The study of a different second-best environment; one in which human capital accumulation can be controlled but not physical capital accumulation. The paper proves that this setting calls for the violation of Friedman rule. In this case, the distortion due to the violation of Friedman rule does alleviate the distortion due to the lack of physical capital accumulation. (iii) The existence of a

\footnotetext{
${ }^{3}$ This is done along the lines of Hahn and Solow (1995). See also Crettez et al. $\quad(1999,2002)$, and Michel and Wigniolle (2005).

${ }^{4}$ Docquier et al.'s (2007) result applies and the relationship between laissez faire and first-best solutions remain the same as in their paper.
} 
negative relationship between money growth rate on the one hand and the endogenous growth rate of the economy on the other. (iv) Non-uniqueness of Friedman rule: A continuum of monetary growth rates and tax rates on consumption during working years result in a zero opportunity cost of holding money. ${ }^{5}$

The paper is related to the vast literature on Friedman rule particularly those written in the context of endogenous growth and/or within the overlapping generations framework. van der Ploeg and Alogoskoufis (1994) referred to earlier is one. Paal and Smith (2000) discuss the suboptimality of Friedman rule in a monetary growth model where spatial separation and limited communication rationalize money holding for transaction purposes. There are no (offsetting) fiscal instruments in their model and the suboptimality of Friedman rule is caused by the impact of bank portfolio reallocations on the real economy. Other similar papers that discusses the effects of monetary growth on the real economy within an endogenous growth framework include Wang and Yip (1992), Gomme (1993), van der Ploeg and Alogoskoufis (1994), Jones and Manuelli (1995), Chang and Lai (2000), Dotsey and Sarte (2000), Chang et al. (2007), and Bhattacharya et al. (2008).

\section{The model and its laissez-faire equilibrium}

Consider the Diamond's (1965) two-period overlapping generations model wherein individuals work in the first period supplying one unit of labor, derive utility from consuming a composite consumption good $c$ in the first period, and $d$ in the second period. There is no bequest motive, and population grows at a constant rate, $n$. Append to this model (i) money holdings and (ii) human capital accumulation as modeled by Docquier et al. (2007). To stay within a two-period formulation, assume that the decisions on human capital accumulation, production, and consumption are all undertaken at the beginning

\footnotetext{
${ }^{5}$ The results in (iii) and (iv) generalize those for Diamond's overlapping generations model with cashin-advance constraint but in the absence of endogenous growth. They are opposite the results obtained with money in the utility function [see Gahvari $(1988,2007)]$.
} 
of period one and in the order stated. ${ }^{6}$ Output of each period can be used for consumption in the same period, or retained with no depreciation, to be used next period as an input either in the educational process of the young or the production process.

\subsection{Education}

At the beginning of time $t$, the young start life with a given amount of human capital, $h_{t-1}$, that they have inherited from their parents. I shall refer to persons born in calendar time $t$ as members of generation $t$. Thus those who are old at time $t$ are members of generation time $t-1$. Education combined with one's inherited human capital determines a worker's effective labor. Thus, investing $e_{t}$ in the young's education raises their effective labor from $h_{t-1}$ to $h_{t}$. The human capital formation technology is characterized by the linear homogeneous function $\Phi\left(e_{t}, h_{t-1}\right)$. That is,

$$
h_{t}=\Phi\left(e_{t}, h_{t-1}\right)=h_{t-1} \varphi\left(\frac{e_{t}}{h_{t-1}}\right) \text {, }
$$

where $\varphi(\cdot) \equiv \Phi(\cdot, 1)$. I assume that $\varphi(\cdot)$ is positive, increasing, and strictly concave; it also satisfies the Inada conditions: $\varphi^{\prime}(0)=\infty$ and $\varphi^{\prime}(\infty)=0 .^{7}$

When deciding on how much to invest in their education, the young have no resources. They thus borrows $e_{t}$ each for their own education from the old of the previous generation. In this way, each young person raises his effective labor from $h_{t-1}$ to $h_{t}$. In deciding how much to educate himself, the individual choose $e_{t}$ to maximize his net earnings. Let $w_{t}$ denote the real wage at time $t$ (measured in units of composite consumption good), and $r_{t}$ the real interest rate. The individual chooses $e_{t}$ to maximize $w_{t} h_{t}-e_{t}\left(1+r_{t}\right)$ subject to (1). This yields a solution for $e_{t}$ characterized by

$$
\varphi^{\prime}\left(\frac{e_{t}}{h_{t-1}}\right)=\frac{1+r_{t}}{w_{t}} .
$$

\footnotetext{
${ }^{6}$ This formulation is a "short cut" to stay within a two-period overlapping generations model. A more realistic formulation allows for three periods, the first of which is dedicated to the education of children.

${ }^{7}$ This process is also a "short-cut" in that one does not model the precise nature of the contribution of a parent's human capital to that of his children and the resources that may have to be spent in this process.
} 
Observe that $\varphi\left(e_{t} / h_{t-1}\right)>1$; otherwise there will be no investment in education.

\subsection{Production}

Production takes place after education. The production technology, which also exhibits constant returns to scale, uses capital, $K_{t}$, and effective labor, $H_{t}$, to produce a composite output, $Y_{t}=F\left(K_{t}, H_{t}\right)$. Let $N_{t}$ denote the number of young persons-equivalently workers - at time $t$, and define output, capital, and effective labor per worker according to $y_{t}=Y_{t} / N_{t}, k_{t}=K_{t} / N_{t}, h_{t}=H_{t} / N_{t}$. The production function can then be presented by $y_{t}=F\left(k_{t}, h_{t}\right)$. Assuming a competitive setting $w_{t}$ and $r_{t}$ are determined according to

$$
\begin{aligned}
w_{t} & =F_{h}\left(k_{t}, h_{t}\right), \\
r_{t} & =F_{k}\left(k_{t}, h_{t}\right) .
\end{aligned}
$$

At the beginning of period $t$, prior to the educational and production decisions, the sum of aggregate capital to be used for educational investment of the young, $N_{t} e_{t}$, and for production, $K_{t}$, is pre-determined from the savings decisions of the old at time $t-1$ when they were young. Moreover, given that the number of young individuals $N_{t}$ is also exogenously given, $e_{t}+k_{t}$ is given at time $t$. With $e_{t}+k_{t}$ given, the additional four equations (1), (2), (3), and (4) determine the equilibrium values for $k_{t}, e_{t}, h_{t}, w_{t}$, and as functions of $h_{t-1}$.

\subsection{Money and the current price level}

Holdings of money is rationalized through a Clower cash-in-advance constraint. I assume that it takes the form of

$$
M_{t} \geqq \alpha N_{t-1} p_{t} d_{t}
$$

where $M_{t}$ is the aggregate stock of money at time $t, p_{t}$ is the price level at time $t$ and $\alpha<1$ is the proportion of the old's consumption that has to be financed through cash. 
The old's money holdings at $t$ consist of two components: their own cash savings from the previous period and a lump-sum money transfer from (or to) the government, $s_{t}$. All money injections to (or subtractions from) the economy are in the form of these lumpsum transfers. The lump-sum transfer to each old person is set equal to a fraction, $\theta$, of his money holdings from the previous period which he carries into the current period. That is,

$$
s_{t}=\theta \frac{M_{t-1}}{N_{t-1}},
$$

and money stock grows at the rate of $\theta$ per period according to

$$
M_{t}=M_{t-1}+N_{t-1} s_{t}=(1+\theta) M_{t-1} .
$$

At the end of the production process, each young person receives $w_{t} h_{t}$ out of which he has to pay his educational loan to the old plus interest, $e_{t}\left(1+r_{t}\right)$, and use the rest for his consumption and savings that will be channeled into the purchase of all real assets and the existing cash in the economy. The resources of the old consist of the educational loan they had given the young plus the associated interest, the capital stock they brought into production process plus interest, their cash holdings, and their lump-sum money transfers. Their budget constraint is given by

$$
p_{t} d_{t}=\frac{p_{t}\left(K_{t}+N_{t} e_{t}\right)\left(1+r_{t}\right)+M_{t-1}}{N_{t-1}}+s_{t}
$$

Assume that the cash constraint (5) is binding so that $M_{t} / N_{t-1} p_{t}=\alpha d_{t}$. Substituting for $d_{t}$ from this relationship into (7), while also substituting $\theta M_{t-1} / N_{t-1}$ for $s_{t}$. Rearranging the terms yields,

$$
\frac{M_{t}}{N_{t}}\left(\frac{1-\alpha}{\alpha}\right)=p_{t}\left(k_{t}+e_{t}\right)\left(1+r_{t}\right)
$$

Equation (8) then determines the price level, $p_{t}$. Observe that $p_{t}$ depends on $M_{t}$, and through (6), on $\theta$. 


\subsection{Consumption and saving}

Observe first that consumption level of the current old, $d_{t}$, is determined through equation (7). It depends on the value of $p_{t}$ (which itself depends on $\theta$ ). Turning to the young, their preferences are represented by

$$
u=u\left(c_{t}, d_{t+1}\right)
$$

The utility function $u(\cdot, \cdot)$ is strictly quasi-concave and twice differentiable. The young consume $c_{t}$ each, buy the existing money stock, $M_{t}$, and save the rest of their income, $K_{t+1}+N_{t+1} e_{t+1}$. Their budget constraint is given by

$$
p_{t} c_{t}+\frac{p_{t}\left(K_{t+1}+N_{t+1} e_{t+1}\right)+M_{t}}{N_{t}}=p_{t} w_{t} h_{t}-p_{t} e_{t}\left(1+r_{t}\right) .
$$

They choose the values of their current consumption,money holdings,and real savings based on their expectation for the future interest rate, $r_{t+1}^{e}$, and the price level, $p_{t+1}^{e}$.

In doing so, the young realize that their expected future consumption $d_{t+1}^{e}$ will have be financed from their savings according to their budget constraint when old

$$
p_{t+1}^{e} d_{t+1}^{e}=\frac{p_{t+1}^{e}\left(K_{t+1}+N_{t+1} e_{t+1}\right)\left(1+r_{t+1}^{e}\right)+M_{t}}{N_{t}}+s_{t+1}
$$

Eliminating $\left(K_{t+1}+N_{t+1} e_{t+1}\right)$ between equation (10) and (11) results in the young's intertemporal budget constraint

$$
c_{t}+\frac{d_{t+1}^{e}}{1+r_{t+1}^{e}}=w_{t} h_{t}-e_{t}\left(1+r_{t}\right)+\left[\frac{p_{t}}{p_{t+1}^{e}\left(1+r_{t+1}^{e}\right)}-1\right] \frac{M_{t}}{N_{t} p_{t}}+\frac{s_{t+1}}{p_{t+1}^{e}\left(1+r_{t+1}^{e}\right)} .
$$

Now to consume $d_{t+1}^{e}$, the young must hold an amount of cash that satisfies the Clower cash constraint

$$
\alpha d_{t+1}^{e}=\frac{M_{t+1}}{N_{t} p_{t+1}^{e}}=\frac{(1+\theta) M_{t}}{N_{t} p_{t}} \frac{p_{t}}{p_{t+1}^{e}} .
$$

Denote the inflation rate by $\pi_{t}$, and the nominal interest rate by $i_{t}$ so that

$$
\begin{aligned}
\frac{p_{t+1}}{p_{t}} & \equiv 1+\pi_{t+1}, \\
1+i_{t+1} & \equiv\left(1+r_{t+1}\right)\left(1+\pi_{t+1}\right) .
\end{aligned}
$$


Using the above notation, applied to expectations, substituting for $M_{t} /\left(N_{t} p_{t}\right)$ from (13) into (12), and simplifying, one arrives at

$$
c_{t}+\frac{1}{1+r_{t+1}^{e}}\left(1+\frac{\alpha i_{t+1}^{e}}{1+\theta}\right) d_{t+1}^{e}=w_{t} h_{t}-e_{t}\left(1+r_{t}\right)+\frac{s_{t+1}}{p_{t+1}^{e}\left(1+r_{t+1}^{e}\right)} .
$$

Observe that not all of the above equations are independent from one another. Moreover, the Clower cash constraint has previously been used in the determination of $k_{t}, e_{t}, h_{t}, w_{t}, r_{t}, M_{t}$, and $p_{t}$. The independent equations that remain for the determination of the laissez-faire equilibrium are (10), (14), (15), and (16).

The problem of the young can then be formulated as that maximizing the utility function (9) subject to the intertemporal budget constraint (16) and the human capital formation function (1), when $s_{t+1}$ is treated as lump sum. This results in the first-order condition

$$
\frac{u_{d}\left(c_{t}, d_{t+1}^{e}\right)}{u_{c}\left(c_{t}, d_{t+1}^{e}\right)}=\frac{1+\alpha i_{t+1}^{e} /(1+\theta)}{1+r_{t+1}^{e}}
$$

which is another independent equation. Two of these five equations, (16) and (17), determine $c_{t}$, and $d_{t+1}^{e}$ as functions of the already determined variables, $e_{t}, h_{t}, w_{t}, r_{t}, p_{t}$, as well as the policy parameters, $s_{t+1}, \theta$, and the expected variables, $r_{t+1}^{e}, p_{t+1}^{e}$, and $i_{t+1}^{e}$. Using equations (14) and (15), one can eliminate $i_{t+1}^{e}$ from the list of expected variables. A perfect foresight assumption, governing the determination of $r_{t+1}^{e}$, and $p_{t+1}^{e}\left(r_{t+1}^{e}=r_{t+1}\right.$ and $\left.p_{t+1}^{e}=p_{t+1}\right)$, closes the model.

As a final observation, note that the determination of $d_{t+1}^{e}$ fixes, via (10), the value of $\left(K_{t+1}+N_{t+1} e_{t+1}\right)$, the aggregate amount of capital to be used for educational investment and for production in period $t+1$. This confirms my previous assumption, when discussing education and production decisions, that this sum is pre-determined at the beginning of each period from the decisions of the previous period. 


\subsection{Dynamics}

First, to simplify the exposition, rewrite the variables of the model as a fraction of effective labor. Denote $\widehat{e}_{t} \equiv e_{t} / h_{t-1}$ and thus rewrite equations (1) and (2) as ${ }^{8}$

$$
\begin{aligned}
h_{t} & =h_{t-1} \varphi\left(\widehat{e}_{t}\right), \\
\varphi^{\prime}\left(\widehat{e}_{t}\right) & =\frac{1+r_{t}}{w_{t}} .
\end{aligned}
$$

Similarly, denote $\widehat{y}_{t}=Y_{t} / H_{t}=y_{t} / h_{t}$ and $\widehat{k}_{t}=K_{t} / H_{t}=k_{t} / h_{t}$. This allows the production function to be represented by $\widehat{y}_{t}=f\left(\widehat{k}_{t}\right)$, where $f(\cdot)$ is positive, increasing, and strictly concave. One can then rewrite equations (3) and (4) as

$$
\begin{aligned}
w_{t} & =f\left(\widehat{k}_{t}\right)-\widehat{k}_{t} f^{\prime}\left(\widehat{k}_{t}\right), \\
r_{t} & =f^{\prime}\left(\widehat{k}_{t}\right) .
\end{aligned}
$$

Observe that the values of $\widehat{e}_{t}$ and $\widehat{k}_{t}$ will be determined as soon as $e_{t}$ and $k_{t}$ are determined.

Now, to examine the dynamic evolution of this economy, consider the following three equations: (10), (16), and (17), where I have replaced the variables in expectation by their "actual" values and dropped all superscripts $T$. First, from the Clower cash constraint, substitute $\alpha d_{t}$ for $M_{t} /\left(N_{t-1} p_{t}\right)$ in equation (10), then divide it by $p_{t} h_{t}$, and substitute in it $\widehat{e}_{t+1}$ for $e_{t+1} / h_{t}, \varphi\left(\widehat{e}_{t+1}\right)$ for $h_{t+1} / h_{t}$, and $\varphi\left(\widehat{e}_{t}\right)$ for $h_{t} / h_{t-1}$. Simplifying yields

$$
(1+n)\left[\widehat{k}_{t+1} \varphi\left(\widehat{e}_{t+1}\right)+\widehat{e}_{t+1}\right]+\frac{\alpha}{1+n} \frac{\widehat{d}_{t}}{\varphi\left(\widehat{e}_{t}\right)}=w_{t}-\left(1+r_{t}\right) \frac{\widehat{e}_{t}}{\varphi\left(\widehat{e}_{t}\right)}-\widehat{c}_{t}
$$

where $\widehat{c_{t}} \equiv c_{t} / h_{t}$ and $\widehat{d_{t}} \equiv d_{t} / h_{t-1}$.

Second, turning to (16), substitute $\theta M_{t} / N_{t}$ for $s_{t+1}, M_{t+1} /(1+\theta)$ for $M_{t}, p_{t+1}(1+$ $\left.r_{t+1}\right)$ for $p_{t}\left(1+i_{t+1}\right), \alpha d_{t+1}$ for $M_{t+1} /\left(p_{t+1} N_{t}\right)$, to rewrite it as

$$
c_{t}+\left[1+\frac{\alpha\left(i_{t+1}-\theta\right)}{1+\theta}\right] \frac{d_{t+1}}{1+r_{t+1}}=w_{t} h_{t}-\left(1+r_{t}\right) e_{t}
$$

\footnotetext{
${ }^{8}$ From now on whenever a "hat" appears over a variable, it denotes that the variable is expressed per unit of effective labor.
} 
Divide this equation by $h_{t}$, and substitute $\varphi\left(\widehat{e}_{t}\right)$ for $h_{t} / h_{t-1}$ to get

$$
\widehat{c}_{t}+\left[1+\frac{\alpha\left(i_{t+1}-\theta\right)}{1+\theta}\right] \frac{\widehat{d}_{t+1}}{1+r_{t+1}}=w_{t}-\left(1+r_{t}\right) \frac{\widehat{e}_{t}}{\varphi\left(\widehat{e}_{t}\right)} .
$$

Finally, assuming that the utility function (9) is homothetic, the marginal rate of substitution between $\widehat{c}_{t}$ and $\widehat{d}_{t+1}$ and between $c_{t}$ and $d_{t+1}$ will be the same. It then follows from the first-order condition (17) that

$$
\frac{u_{d}\left(\widehat{c}_{t}, \widehat{d}_{t+1}\right)}{u_{c}\left(\widehat{c}_{t}, \widehat{d}_{t+1}\right)}=\frac{1+\alpha i_{t+1} /(1+\theta)}{1+r_{t+1}}
$$

Now eliminate $\widehat{c}_{t}$ between equations (18), (19), (20), and solve the remaining two equations for $\widehat{k}_{t+1}$ and $\widehat{d}_{t+1}$. Noting that $i_{t+1}$ depends on $\pi_{t+1}$ and $r_{t+1}, w_{t}$ and $r_{t}$ on $\widehat{k}_{t}$, and $r_{t+1}$ on $\widehat{k}_{t+1}$, one will get: $\widehat{k}_{t+1}=\widehat{k}_{t+1}\left(\widehat{k}_{t}, \widehat{d}_{t}, \widehat{e}_{t+1}, \widehat{e}_{t}, \pi_{t+1}\right)$ and $\widehat{d}_{t+1}=$ $\widehat{d}_{t+1}\left(\widehat{k}_{t}, \widehat{d}_{t}, \widehat{e}_{t+1}, \widehat{e}_{t}, \pi_{t+1}\right)$. Then observe, from the Clower cash constraint (13), that

$$
\frac{1+\theta}{1+n} \frac{d_{t}}{d_{t+1}}=1+\pi_{t+1}
$$

Multiply the numerator by $h_{t-1} / h_{t-1}$ and the denominator of this relationship by $h_{t} / h_{t}$ to rewrite it as

$$
\frac{1+\theta}{1+n} \frac{h_{t-1} d_{t} / h_{t-1}}{h_{t} d_{t+1} / h_{t}}=\frac{1+\theta}{1+n} \frac{1}{\varphi\left(\widehat{e}_{t}\right)} \frac{\widehat{d}_{t}}{\widehat{d}_{t+1}}=1+\pi_{t+1}
$$

Using (21) to eliminate $\pi_{t+1}$ in $\widehat{k}_{t+1}=\widehat{k}_{t+1}\left(\widehat{k}_{t}, \widehat{d}_{t}, \widehat{e}_{t+1}, \widehat{e}_{t}, \pi_{t+1}\right)$ and $\widehat{d}_{t+1}=\widehat{d}_{t+1}\left(\widehat{k}_{t}, \widehat{d}_{t}\right.$, $\left.\widehat{e}_{t+1}, \widehat{e}_{t}, \pi_{t+1}\right)$, one gets two new expressions for $\widehat{k}_{t+1}$ and $\widehat{d}_{t+1}$ which I show, with an abuse of notation, by $\widehat{k}_{t+1}=\widehat{k}_{t+1}\left(\widehat{k}_{t}, \widehat{d}_{t}, \widehat{e}_{t+1}, \widehat{e}_{t}\right)$ and $\widehat{d}_{t+1}=\widehat{d}_{t+1}\left(\widehat{k}_{t}, \widehat{d}_{t}, \widehat{e}_{t+1}, \widehat{e}_{t}\right)$. Finally, recall that the first-order condition (2) determines $\widehat{e}_{t}$ as a function of $\widehat{k}_{t}$, and thus $\widehat{e}_{t+1}$ as a function of $\widehat{k}_{t+1}$. Using these relationships in $\widehat{k}_{t+1}=\widehat{k}_{t+1}\left(\widehat{k}_{t}, \widehat{d}_{t}, \widehat{e}_{t+1}, \widehat{e}_{t}\right)$ and $\widehat{d}_{t+1}=\widehat{d}_{t+1}\left(\widehat{k}_{t}, \widehat{d}_{t}, \widehat{e}_{t+1}, \widehat{e}_{t}\right)$ leads to a pair of first-order difference equations of the form

$$
\begin{aligned}
& \widehat{k}_{t+1}=\Psi\left(\widehat{k}_{t}, \widehat{d}_{t}\right) \\
& \widehat{d}_{t+1}=\Phi\left(\widehat{k}_{t}, \widehat{d}_{t}\right)
\end{aligned}
$$


The system of difference equations (22)-(23) determines the dynamic path of the economy. Moreover, the economy tends to a balanced growth path if equations (22)(23) have a steady state solution and if it is stable. Under the latter two assumptions, the steady state values of $\left(\widehat{k}_{t}, \widehat{d}_{t}\right)$ will be the rest point of equations $(22)-(23) .{ }^{9}$

To examine the (local) stability properties of the steady-state solution, I linearize the system of difference equations $(22)-(23)$ around the steady-state solution $(\widehat{k}, \widehat{d})$ according to

$$
\left(\begin{array}{c}
\widehat{k}_{t+1}-\widehat{k} \\
\widehat{d}_{t+1}-\widehat{d}
\end{array}\right)=\left(\begin{array}{cc}
\Psi_{k}(\widehat{k}, \widehat{d}) & \Psi_{d}(\widehat{k}, \widehat{d}) \\
\Phi_{k}(\widehat{k}, \widehat{d}) & \Phi_{d}(\widehat{k}, \widehat{d})
\end{array}\right)\left(\begin{array}{c}
\widehat{k}_{t}-\widehat{k} \\
\widehat{d}_{t}-\widehat{d}
\end{array}\right) \equiv \Omega\left(\begin{array}{c}
\widehat{k}_{t}-\widehat{k} \\
\widehat{d}_{t}-\widehat{d}
\end{array}\right)
$$

where $\Psi_{k}, \Psi_{d}, \Phi_{k}$, and $\Phi_{d}$ denote the partial derivatives of $\Psi(\cdot)$ and $\Phi(\cdot)$ with respect to $k$ and $d$. The dynamic path given by (24) converges to a steady state as $t$ increases (i.e., $\widehat{k}_{t}-\widehat{k}$ and $\widehat{d}_{t}-\widehat{d}$ tend to zero), if at time $t=0$, the initial values of $\widehat{k}_{0}$ and $\widehat{d}_{0}$ are such that $\left(\widehat{k}_{0}-\widehat{k}, \widehat{d}_{0}-\widehat{d}\right)$ is in the space spanned by the eigenvectors of $\Omega$ that are associated with the eigenvalues of $\Omega$ with modulus smaller than one. Now, at $t=0$, the value of $\widehat{k}_{0}$ is pre-determined. However, the value of $\widehat{d}_{0}$ depends on $p_{0}$. Consequently, the system will be stable for any value of $p_{0}$ if $\Omega$ possesses two eigenvalues with modulus less than one. If there is only one eigenvalue with a modulus less than one, then there will be one value for $p_{0}$ and a unique path which leads to the steady state.

\footnotetext{
${ }^{9}$ The regularity conditions one imposes on preferences and the technology ensure only that positive values exist for the variables along a solution path. There is no guarantee, however, that there exists a steady-state solution to which the system is driven.
} 


\subsection{Balanced growth}

At the steady state, equations (20), (19), (18), (21), (15), (2), (4), and (3) are simplified to

$$
\begin{aligned}
& \frac{u_{d}(\widehat{c}, \widehat{d})}{u_{c}(\widehat{c}, \widehat{d})}=\frac{1+\alpha i /(1+\theta)}{1+r}, \\
& \widehat{c}+\left[1+\frac{\alpha(i-\theta)}{1+\theta}\right] \frac{\widehat{d}}{1+r}=w-(1+r) \frac{\widehat{e}}{\varphi(\widehat{e})}, \\
& (1+n)[\widehat{k} \varphi(\widehat{e})+\widehat{e}]+\frac{\alpha}{1+n} \frac{\widehat{d}}{\varphi(\widehat{e})}=w-(1+r) \frac{\widehat{e}}{\varphi(\widehat{e})}-\widehat{c} \\
& 1+\pi=\frac{1+\theta}{(1+n) \varphi(\widehat{e})}, \\
& 1+i=(1+r) \frac{1+\theta}{(1+n) \varphi(\widehat{e})}, \\
& \varphi^{\prime}(\widehat{e})=\frac{1+r}{w}, \\
& r=f^{\prime}(\widehat{k}) \\
& w=f(\widehat{k})-\widehat{k} f^{\prime}(\widehat{k}) .
\end{aligned}
$$

These equations determine the steady state values of real variables $\widehat{c}, \widehat{d}, \widehat{e}, \widehat{k}, w, r$, and monetary variables $i$, and $\pi$. Observe that while these values remain unchanged, the values of the other variables of the model grow over time at a constant rate. This is the balanced growth path of the economy. Specifically, let $g \equiv \varphi(\widehat{e})-1$. Then, $e_{t}=(1+g) e_{t-1}, h_{t}=(1+g) h_{t-1}, k_{t}=(1+g) k_{t-1}, c_{t}=(1+g) c_{t-1}, d_{t}=(1+g) d_{t-1}$, and $K_{t}=(1+n)(1+g) K_{t-1}$. Utility also grows over time. In particular, if the utility function is homogeneous of degree $\beta, u\left(c_{t}, d_{t+1}\right)=u\left(h_{t} \widehat{c}_{t}, h_{t} \widehat{d}_{t+1}\right)=h_{t}^{\beta} u\left(\widehat{c}_{t}, \widehat{d}_{t+1}\right)$. On the balanced growth path, $u\left(c_{t+1}, d_{t+2}\right)=h_{t+1}^{\beta} u\left(\widehat{c}_{t+1}, \widehat{d}_{t+2}\right)=\left(h_{t+1} / h_{t}\right)^{\beta} h_{t}^{\beta} u\left(\widehat{c}_{t}, \widehat{d}_{t+1}\right)=$ $(1+g)^{\beta} u\left(c_{t}, d_{t+1}\right) \cdot{ }^{10}$ Thus all per capita terms, $h_{t}, e_{t}, k_{t}, c_{t}, d_{t}$, increase by a factor of

\footnotetext{
${ }^{10}$ With $s_{t+1}=\theta M_{t} / N_{t}$,

$$
\frac{s_{t+1}}{s_{t}}=\frac{\theta M_{t} / N_{t}}{\theta M_{t-1} / N_{t-1}}=\frac{M_{t}}{M_{t-1}} \frac{N_{t-1}}{N_{t}}=\frac{1+\theta}{1+n} .
$$
}


$(1+g)$ per period and the utility increases by a factor of $(1+g)^{\beta}$. Note that $\beta>0 .{ }^{11}$

The following proposition summarizes these results:

Proposition 1 Consider a version of Diamond's (1965) overlapping-generations wherein each generation's human capital is determined via the level they inherit from their parents and their own educational attainment. Assume further that money is an alternative asset to physical capital and required for second period transactions. On a balanced growth path, per capita educational expenditures, human capital, physical capital, consumption during working years, and consumption during retirement all grow at a constant rate $g$ determined by the human capital production function. The monetary variables of the economy, the inflation rate and the nominal rate of interest, remain constant and vary with the rate of money growth, $\theta$. Equations (25)-(32) characterize the laissez faire balanced growth path of the economy.

\section{First best}

Let the social welfare function be presented by the discounted sum of the average of all generations' lifetime utilities. The first best is then characterized by maximizing this function subject to every generation's human capital formation and resource constraint. The human capital formation is given by equation (1); the resource constraint for the generation born at time $t$ is given by

$$
K_{t}+F\left(K_{t}, H_{t}\right)=N_{t} c_{t}+N_{t-1} d_{t}+K_{t+1}+N_{t+1} e_{t+1},
$$

Observe also that the above implies, using (21),

$$
\frac{s_{t+1} / p_{t+1} h_{t}}{s_{t} / p_{t} h_{t-1}}=\frac{s_{t+1}}{s_{t}} \frac{p_{t}}{p_{t+1}} \frac{h_{t-1}}{h_{t}}=\frac{1+\theta}{1+n} \frac{1}{1+\pi_{t+1}} \frac{1}{\varphi\left(\widehat{e}_{t}\right)}=\frac{\widehat{d}_{t+1}}{\widehat{d}_{t}} .
$$

Now with $\widehat{d}_{t+1} / \widehat{d}_{t}=1$ in the steady state, $s_{t+1} / p_{t+1} h_{t}$ remains constant over time.

${ }^{11}$ Otherwise, with $g>0$, we have $c_{t}$ and $d_{t+1}$ increasing per period, while $u\left(c_{t}, d_{t+1}\right)$ remains the same or is decreasing. 
which one can alternatively write, by dividing it by $N_{t}$, as

$$
k_{t}+h_{t} f\left(\frac{k_{t}}{h_{t}}\right)=c_{t}+\frac{1}{1+n} d_{t}+(1+n)\left(k_{t+1}+e_{t+1}\right)
$$

The Lagrangian expression for this optimization problem can then be written as,

$$
\begin{aligned}
£ \equiv & \sum_{t=0}^{\infty} \frac{1}{(1+\rho)^{t}}\left\{u\left(c_{t}, d_{t+1}\right)+\mu_{t}\left[h_{t} \varphi\left(\frac{e_{t+1}}{h_{t}}\right)-h_{t+1}\right]\right. \\
& \left.+\lambda_{t}\left[k_{t}+h_{t} f\left(\frac{k_{t}}{h_{t}}\right)-c_{t}-\frac{1}{1+n} d_{t}-(1+n)\left(k_{t+1}+e_{t+1}\right)\right]\right\}
\end{aligned}
$$

where $\rho \in(0,1)$ is the discount factor reflecting the "planner's" social time preference, and $\mu_{t} /(1+\rho)^{t}$ and $\lambda_{t} /(1+\rho)^{t}$ are the multipliers associated with the resource constraint and the human capital equation at time $t$. The first order conditions with respect to $c_{t}, d_{t+1}, h_{t+1}, k_{t+1}$, and $e_{t+1}$, are

$$
\begin{aligned}
u_{c}\left(c_{t}, d_{t+1}\right) & =\lambda_{t}, \\
u_{d}\left(c_{t}, d_{t+1}\right) & =\frac{\lambda_{t+1}}{(1+n)(1+\rho)}, \\
(1+\rho) \mu_{t} & =\lambda_{t+1}\left[f\left(\widehat{k}_{t+1}\right)-\widehat{k}_{t+1} f^{\prime}\left(\widehat{k}_{t+1}\right)\right]+\mu_{t+1}\left[\varphi\left(\widehat{e}_{t+2}\right)-\widehat{e}_{t+2} \varphi^{\prime}\left(\widehat{e}_{t+2}\right)\right], \\
\lambda_{t}(1+\rho)(1+n) & =\lambda_{t+1}\left[1+f^{\prime}\left(\widehat{k}_{t+1}\right)\right], \\
\mu_{t} \varphi^{\prime}\left(\widehat{e}_{t+1}\right) & =\lambda_{t}(1+n) .
\end{aligned}
$$

Finally, the transversality condition is:

$$
\lim _{t \rightarrow \infty} \frac{\lambda_{t} k_{t+1}+\mu_{t} h_{t+1}}{(1+\rho)^{t}}=0 .
$$

In characterizing the optimal values of the economic variables, I originally do not mix the implications of either (37) or (38) with those of other first-order conditions of the problem. This facilitates the characterization of second-best outcomes without the instruments for controlling $k_{t}$ and $e_{t}$ which I shall discuss later. Thus derive an expression for $\lambda_{t+1} / \lambda_{t}$ once from (35) by writing it for $t+1$ and $t$ and dividing one by 
the other, and once from dividing (35) by (34). One gets the following two equations

$$
\begin{aligned}
\frac{\lambda_{t+1}}{\lambda_{t}} & =\frac{u_{d}\left(c_{t}, d_{t+1}\right)}{u_{d}\left(c_{t-1}, d_{t}\right)}=\frac{h_{t}^{\beta-1} u_{d}\left(\widehat{c}_{t}, \widehat{d}_{t+1}\right)}{h_{t-1}^{\beta-1} u_{d}\left(\widehat{c}_{t-1}, \widehat{d}_{t}\right)}=\left[\varphi\left(\widehat{e}_{t}\right)\right]^{\beta-1} \frac{u_{d}\left(\widehat{c}_{t}, \widehat{d}_{t+1}\right)}{u_{d}\left(\widehat{c}_{t-1}, \widehat{d}_{t}\right)}, \\
\frac{\lambda_{t+1}}{\lambda_{t}} & =(1+n)(1+\rho) \frac{u_{d}\left(c_{t}, d_{t+1}\right)}{u_{c}\left(c_{t}, d_{t+1}\right)}=(1+n)(1+\rho) \frac{u_{d}\left(\widehat{c}_{t}, \widehat{d}_{t+1}\right)}{u_{c}\left(\widehat{c}_{t}, \widehat{d}_{t+1}\right)} .
\end{aligned}
$$

It then follows from (40)-(41) that

$$
\frac{u_{d}\left(c_{t}, d_{t+1}\right)}{u_{c}\left(c_{t}, d_{t+1}\right)}=\frac{\left[\varphi\left(\widehat{e}_{t}\right)\right]^{\beta-1}}{(1+n)(1+\rho)} \frac{u_{d}\left(\widehat{c}_{t}, \widehat{d}_{t+1}\right)}{u_{d}\left(\widehat{c}_{t-1}, \widehat{d}_{t}\right)}
$$

Next, substituting from (4) in (37) yields $\lambda_{t+1} / \lambda_{t}=(1+\rho)(1+n) /\left(1+r_{t+1}\right)$. Equating this to the expression for $\lambda_{t+1} / \lambda_{t}$ in (41) and using (42)

$$
1+r_{t+1}=\frac{(1+n)(1+\rho)}{\left[\varphi\left(\widehat{e}_{t}\right)\right]^{\beta-1}} \frac{u_{d}\left(\widehat{c}_{t-1}, \widehat{d}_{t}\right)}{u_{d}\left(\widehat{c}_{t}, \widehat{d}_{t+1}\right)} .
$$

Finally, use equation (38) to substitute for $\mu_{t}$ and $\mu_{t+1}$ into (36). Divide the resulting equation by $\lambda_{t}$, substitute for $\lambda_{t+1} / \lambda_{t}$ from (40), and manipulate to arrive at

$\varphi^{\prime}\left(\widehat{e}_{t+1}\right)=\frac{1+n}{w_{t+1}}\left\{\left[\varphi\left(\widehat{e}_{t}\right)\right]^{1-\beta}(1+\rho) \frac{u_{d}\left(\widehat{c}_{t-1}, \widehat{d}_{t}\right)}{u_{d}\left(\widehat{c}_{t}, \widehat{d}_{t+1}\right)}-\frac{\varphi^{\prime}\left(\widehat{e}_{t+1}\right)}{\varphi^{\prime}\left(\widehat{e}_{t+2}\right)}\left[\varphi\left(\widehat{e}_{t+2}\right)-\widehat{e}_{t+2} \varphi^{\prime}\left(\widehat{e}_{t+2}\right)\right]\right\}$.

\subsection{Balanced growth}

On the balanced growth path, $\widehat{c}_{t}$ and $\widehat{d}_{t+1}$ remain constant over time so that equations (42), (43), and (44) simplify to

$$
\begin{aligned}
\frac{u_{d}(\widehat{c}, \widehat{d})}{u_{c}(\widehat{c}, \widehat{d})} & =\frac{1}{(1+n)(1+\rho)[\varphi(\widehat{e})]^{1-\beta}} \\
1+r & =(1+n)(1+\rho)[\varphi(\widehat{e})]^{1-\beta} \\
\varphi^{\prime}(\widehat{e}) & =\frac{1+n}{w}\left\{(1+\rho)[\varphi(\widehat{e})]^{1-\beta}-\left[\varphi(\widehat{e})-\widehat{e} \varphi^{\prime}(\widehat{e})\right]\right\} .
\end{aligned}
$$


Now, given that on a balanced-growth path the transversality condition (39) reduces to $^{12}$

$$
\frac{[\varphi(\widehat{e})]^{\beta}}{1+\rho}<1
$$

in what follows I assume $\beta<1 .^{13}$

Equation (45) shows the first-best marginal rate of intertemporal substitution in consumption. It is the counterpart of equation (17) for the laissez faire. For the two be the same, not only (46) must hold but $i=0$ so that the opportunity cost of holding money is zero (as required by Friedman rule). Equation (46) is the modified golden rule condition; this is generally not satisfied in the laissez faire.

Substituting from equation (46) into equation (47), one gets

$$
\varphi^{\prime}(\widehat{e})=\frac{1+r}{w}-\frac{(1+n)\left[\varphi(\widehat{e})-\widehat{e} \varphi^{\prime}(\widehat{e})\right]}{w} .
$$

This is the counterpart of equation (2). The two differ in that the laissez faire equation does not include the right-hand side terms in braces. This reflects the externality that parents bestow on their children by educating themselves. Recall that education increases one's human capital which also enhances the human capital of one's children. Parents do not take this externality into account when deciding on their own educational attainment. Observe also that this is a positive externality. The above equation is in accordance with this in that with $\varphi(\cdot)$ being concave, $\varphi(\widehat{e})-\widehat{e} \varphi^{\prime}(\widehat{e})>0$ so that $\varphi^{\prime}(\widehat{e})<[1+r] / w$.

With the first-best allocations being the same as in Docquier et al. (2007), it is plain that the introduction of money leaves the relationship between laissez faire and first-best solutions intact as in their model. That is, comparison of the first-best values of $(\widehat{k}, \widehat{e})$, which vary with the social planner's discount rate, with their laissez-faire counterparts reveals three possible regimes: First-best values are larger for both $\widehat{k}$ and $\widehat{e}$; first-best

\footnotetext{
${ }^{12}$ Using (46), condition $[\varphi(\widehat{e})]^{\beta}<1+\rho$ also implies $\varphi(\widehat{e})<(1+r) /(1+n)$ so that at the first best, $r>n$.

${ }^{13}$ This assumption makes the satisfaction of (48) easier; it is neither necessary nor sufficient for it.
} 
value of $\widehat{k}$ is smaller or equal, and first-best value of $\widehat{e}$ is larger; and (iii) first-best values are smaller for both $\widehat{k}$ and $\widehat{e}$ (with the first-best values moving from (i) to (iii) as the utility of future generations is discounted more and more).

\subsection{Decentralization}

Decentralization of the first-best requires the use of a number of fiscal instruments, in particular, generation-specific lump-sum taxes and a subsidy on educational expenditures. Let $z_{t}^{y}$ and $z_{t}^{o}$ denote lump sum taxes imposed at time $t$ on the young of generation $T$ and the old of generation $T-1$, and $\sigma$ the rate of subsidy on educational expenditures. These taxes are related through the government's budget constraint so that

$$
N_{t} z_{t}^{y}+N_{t-1} z_{t}^{o}-N_{t} \sigma\left(1+r_{t}\right) e_{t}=0
$$

Or, dividing by $N_{t-1}$,

$$
(1+n)\left[z_{t}^{y}-\sigma\left(1+r_{t}\right) e_{t}\right]+z_{t}^{o}=0 .
$$

Next dividing (50) by $h_{t}$ yields

$$
(1+n)\left[\widehat{z}_{t}^{y}-\sigma\left(1+r_{t}\right) \frac{\widehat{e}_{t}}{\varphi\left(\widehat{e}_{t}\right)}\right]+\frac{\widehat{z}_{t}^{o}}{\varphi\left(\widehat{e}_{t}\right)}=0
$$

where $\widehat{z}_{t}^{y}=z_{t}^{y} / h_{t}$ and $\widehat{z}_{t}^{o}=z_{t}^{o} / h_{t-1}$. Observe also that $\widehat{z}_{t}^{y}$ and $\widehat{z}_{t+1}^{o}$ remain invariant on the balanced growth path.so that $z_{t}^{y}=(1+g) z_{t-1}^{y}$ and $z_{t}^{o}=(1+g) z_{t-1}^{o}$.

Allowing for the above tax rates, equations (26), (27), and (29) change to

$$
\begin{aligned}
& \widehat{c}+\left[1+\frac{\alpha(i-\theta)}{1+\theta}\right] \frac{\widehat{d}}{1+r}=w-(1-\sigma)(1+r) \frac{\widehat{e}}{\varphi(\widehat{e})}-\widehat{z}^{y}-\frac{\widehat{z}^{o}}{1+r}, \\
& (1+n)[\widehat{k} \varphi(\widehat{e})+\widehat{e}]+\frac{\alpha}{1+n} \frac{\widehat{d}}{\varphi(\widehat{e})}=w-(1-\sigma)(1+r) \frac{\widehat{e}}{\varphi(\widehat{e})}-\widehat{c}-\widehat{z}^{y}, \\
& \varphi^{\prime}(\widehat{e})=\frac{(1-\sigma)(1+r)}{w} .
\end{aligned}
$$

The remaining steady-state equations in (25)-(32) do not change. Thus the market solutions for $\widehat{c}, \widehat{d}, \widehat{e}, \widehat{k}, w, r, i$, and $\pi$ are now found from equations (25), (28), (29), (31), 
(32), and (52)-(54). To have these equations lead to the first-best balanced growth path characterized by (45)-(46), the policy instruments must be set as follows. First, lump-sum taxes $z^{y}, z^{o}$ must be set such that the modified golden rule (46) is attained. ${ }^{14}$ This requirement is commonplace in overlapping generations models. Second, to have the first best condition (47), or (49), satisfied, a subsidy is required on the purchase of $e$. The subsidy rate is found from (47) and (54) to be $\mathrm{e}^{15}$

$$
\sigma=\frac{1+r-(1+n)(1+\rho)[\varphi(\widehat{e})]^{1-\beta}}{1+r}+\frac{(1+n)\left[\varphi(\widehat{e})-\widehat{e} \varphi^{\prime}(\widehat{e})\right]}{1+r},
$$

where $\widehat{e}$ and $r$ take their first-best values. Observe also that in the first best, with condition (46) satisfied, the above relationship is simplified to

$$
\sigma=\frac{(1+n)\left[\varphi(\widehat{e})-\widehat{e} \varphi^{\prime}(\widehat{e})\right]}{1+r} .
$$

Finally, attaining (45) is predicated on the well-known result in the money literature that at the optimum there should be no opportunity cost in holding money; that is that $i$ must be equal to zero. To have (45) satisfied, one must set $i=0$ in equation (25). The implication of this for the rate of money growth is straightforward. Substituting $i=0$ in equation $(15)$ yields $(1+r)(1+\pi)=1$ so that from $(46)$

$$
1+\pi=\frac{1}{(1+\rho)(1+n)[\varphi(\widehat{e})]^{1-\beta}}
$$

It the follows from (28) that

$$
\theta=\frac{[\varphi(\widehat{e})]^{\beta}}{1+\rho}-1<0,
$$

where $\widehat{e}$ is set at its first-best value. The sign of $\theta$ follows from the transversality condition (48).

The following proposition summarizes the results of this section.

\footnotetext{
${ }^{14}$ To be precise, one needs to set either $z^{y}$ or $z^{o}$; the other is determined through the government's budget constraint (51).

${ }^{15}$ In the presence of the subsidy, the young choose $\widehat{e}_{t}$ at $t$ to maximize $w_{t} \varphi\left(\widehat{e}_{t}\right)-\left(1+r_{t}\right)(1-\sigma) \widehat{e}_{t}$. This yields, in the steady state,

$$
\varphi^{\prime}(\widehat{e})=\frac{(1+r)(1-\sigma)}{w} .
$$
}


Proposition 2 The decentralization of the first-best balanced growth path requires generation specific lump-sum taxes, a subsidy on educational expenditures given by equation (55), and the satisfaction of Friedman rule that requires the opportunity cost of holding money to be zero.

\section{Second best with control of physical capital}

Assume now that educational subsidies are unavailable so that the level of investment in education is not optimal. The question I want to address is if the Friedman rule continues to be optimal as long as the government can control the level of physical capital in the economy. To answer this question, I first characterize the second-best allocation when $k$ can be controlled but not $e$. The formulation of this problem is exactly as that in the first best with the sole difference of not being able to optimize over $e$. The optimization problem is summarized by the Lagrangian (33) where the optimization is done with respect to $c_{t}, d_{t+1}, k_{t+1}$, and $h_{t+1}$. The corresponding first-order conditions are (34), (35), (37) and (36). Specifically, first-order condition (38) with respect to $e_{t+1}$ does not hold which means equation (44) does not hold. The equations that characterize this second best are (42) and (43) and their corresponding balanced growth versions, equations (45) and (46). This also means that, as with the first-best, the second-best solution satisfies the no intertemporal consumption distortion, despite the fact that the choice of $e$ is distorted, and the modified golden rule.

Interestingly, as long as one can control $\widehat{k}$ and thus $r=f^{\prime}(\widehat{k})$, the condition for an undistorted intertemporal consumption decision remains $i=0$. Given any $\widehat{e}$, setting $r=(1+n)(1+\rho)[\varphi(\widehat{e})]^{1-\beta}-1$ ensures that the modified golden rule condition (46) is satisfied. Setting $i=0$ on top of this ensures that the intertemporal consumption decision remains undistorted. This indicates the optimality of the Friedman rule in the second-best as well. We have: 
Proposition 3 Friedman rule holds in a second-best environment wherein the levels of education and human capital are suboptimal, as long as physical capital can be controlled and the modified golden rule is satisfied.

\subsection{Why Friedman rule?}

Given our second-best environment, one may wonder why introducing an additional distortion through the violation of the Friedman rule does not improve welfare. The answer lies in the fact the violation of the Friedman rule, in either direction, will not alleviate the existing distortion due to the non-optimality of educational. To demonstrate this, first observe first that in the second-best the relationship between $\widehat{e}$ and $\widehat{k}$ is governed by the laissez-fair condition (30) and in the first-best by equation (49). These relationships imply that, for any given same value of $\widehat{k}$,

$$
\begin{aligned}
& \text { In the SB: } \varphi^{\prime}(\widehat{e})=\frac{1+f^{\prime}(\widehat{k})}{w}, \\
& \text { In the FB: } \varphi^{\prime}(\widehat{e})=\frac{1+f^{\prime}(\widehat{k})}{w}-\frac{(1+n)\left[\varphi(\widehat{e})-\widehat{e} \varphi^{\prime}(\widehat{e})\right]}{w}<\frac{1+f^{\prime}(\widehat{k})}{w},
\end{aligned}
$$

where the inequality sign follows from the concavity of $\varphi(\cdot)$. It then follows from equations (57)-(58) that $\varphi^{\prime}\left(\widehat{e}^{F B}(\widehat{k})\right)<\varphi^{\prime}\left(\widehat{e}^{S B}(\widehat{k})\right)$ where superscripts $F B$ and $S B$ denote first best and second best. The concavity of $\varphi(\cdot)$ then implies $\widehat{e}^{F B}(\widehat{k})>\widehat{e}^{S B}(\widehat{k})$ so that the graph of $\widehat{e}^{F B}(\widehat{k})$ is above graph $\widehat{e}^{S B}(\widehat{k})$.

Next, differentiate equation (57) with respect to $\widehat{k}$. This yields

$$
\frac{d \widehat{e}}{d \widehat{k}}=\frac{w+(1+r) \widehat{k}}{w^{2}} \frac{f^{\prime \prime}(\widehat{k})}{\varphi^{\prime \prime}(\widehat{e})}>0 .
$$

Intuitively, as $\widehat{k}$ increases, $(1+r) / w$ declines and this lowers the cost of borrowing to educate oneself relative to returns to education. This, in turn, increases the demand for education. It follows from equation (59) that the graph of (57) slopes upward. Similarly, one can easily establish, through differentiation, that the graph of (58), relating $\widehat{e}$ and $\widehat{k}$ in the first best, also slopes upward. On the other hand, differentiation establishes that 


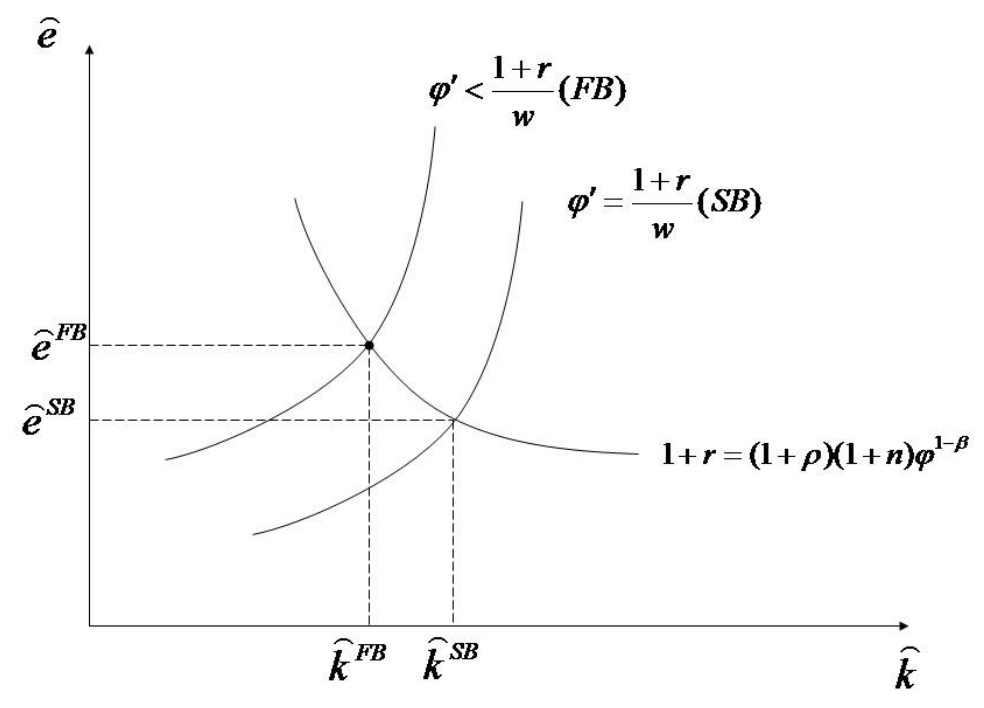

Figure 1:

the graph of the modified golden rule condition (46) which holds both in the second best as well as first best, slopes downward. Diagram 1 depicts these three graphs.

The upshot of all this is that the first-best value of $\widehat{e}$ exceeds its second-best value, while the first-best value of $\widehat{k}$ is smaller than its second-best value. We have

$$
\begin{aligned}
& \widehat{e}^{S B}<\widehat{e}^{F B}, \\
& \widehat{k}^{S B}>\widehat{k}^{F B} .
\end{aligned}
$$

These inequalities show that whereas the second-best value of $\widehat{e}$ must increase, the second-best value of $\widehat{k}$ must decrease in order to move the second-best equilibrium "closer" to the first-best equilibrium.

Now observe that the laissez-fair condition (30), which governs the relationship between $\widehat{e}$ and $\widehat{k}$ in the second best, is independent of $\theta$. Specifically, one has $d \widehat{e} / d \theta=$ 
$(d \widehat{e} / d \widehat{k})(d \widehat{k} / d \theta)$. This implies that while a change in $\theta$ changes the equilibrium values of $\widehat{e}$ and $\widehat{k}$, it will leave the relationship between the two intact. In terms of Diagram 1 , a change in $\theta$ moves the second-best equilibrium along the graph of $\varphi^{\prime}(\widehat{e})=$ $\left(1+f^{\prime}(\widehat{k})\right) / w$. Put differently, changing $\theta$ moves the equilibrium values of $\widehat{e}$ and $\widehat{k}$ in the same direction. Either it increases both $\widehat{e}$ and $\widehat{k}$ or decreases them. This means that violating the Friedman rule has two offsetting effects. It alleviates one of the existing distortions in the variables $\widehat{e}$ or $\widehat{k}$, but exacerbates the other one. Considering that the violation of the Friedman rule is itself an added source of distortion, in one's intertemporal choice, there is no obvious net benefit to it.

\subsection{First versus second best}

The finding that $\widehat{e}^{S B}<\widehat{e}^{F B}$ and $\widehat{k}^{S B}>\widehat{k}^{F B}$ allows one to compare the first-best and second-best values of the other variables of interest. Specifically, with $\widehat{k}^{S B}>\widehat{k}^{F B}$, it follows that $r^{S B}<r^{F B}$ and $w^{S B}>w^{F B}$. However, at any given time $t$, it is not $w$ that matters to the individual but $w h_{t}$. Now $h_{t}$ grows at the rate of $g^{F B}=\varphi\left(\widehat{e}^{F B}\right)-1$ in the first best and $g^{S B}=\varphi\left(\widehat{e}^{S B}\right)-1$ in the second best, with $g^{S B}<g^{F B}$. Finally, observe that while $i=0$ in both first and second best, the corresponding money growth rate that induces this differs across the two equilibria. Because condition (43) holds in the second best as well, the corresponding monetary growth rate continues to be given by equation (46)

$$
\theta=\frac{[\varphi(\widehat{e})]^{\beta}}{1+\rho}-1 .
$$

With $\widehat{e}^{S B}<\widehat{e}^{F B}$, the optimal monetary growth rate - the Friedman rule calls for a smaller monetary growth rate. That is

$$
\theta^{S B}<\theta^{F B}<0
$$

These results are summarized as: 
Proposition 4 Let $\widehat{k}$ denote physical capital to human capital ratio, $g$ denote the growth rate of the economy, $\theta$ denote the money growth rate, and superscripts $F B$ and $S B$ denote first- and second-best solutions. Then, $\widehat{k}^{S B}>\widehat{k}^{F B}, \widehat{e}^{S B}<\widehat{e}^{F B}, g^{S B}<g^{F B}$, and $\theta^{S B}<\theta^{F B}<0$.

\section{Second best without control of physical capital}

Assume now that differential lump-sum tax and transfers are not feasible and the government cannot control the level of physical capital in the economy. However, educational subsidies are available and $\widehat{e}$ is set optimally. To characterize this second-best equilibrium, one can again formulate the problem as in the first best with the exception of not optimizing over $k$. Specifically, the optimization problem is summarized by the Lagrangian (33) where the optimization is done with respect to $c_{t}, d_{t+1}, h_{t+1}$, and $e_{t+1}$. The first-order condition that does not hold in this case is (37) and thus (43). The equations that characterize this second-best allocation are then the same as (45) and (47): One continues to require an undistorted intertemporal consumption decision and an undistorted decision concerning educational expenditures.

Unlike the previous two cases, the Friedman rule of $i=0$ no longer ensures that equation (45), requiring an undistorted intertemporal consumption decision, is satisfied. This arises because the modified golden rule condition (46) does not hold in this second best. Put differently, bringing about an undistorted intertemporal consumption decision when the modified golden rule is not satisfied, requires that Friedman rule is violated. Indeed, from equations (25) and (29), condition (45) is satisfied if

$$
\begin{aligned}
i & =\frac{(1+r)-(1+\rho)(1+n)[\varphi(\widehat{e})]^{1-\beta}}{\alpha(1+r)(1+\rho)[\varphi(\widehat{e})]^{-\beta}-\left\{(1+r)-(1+\rho)(1+n)[\varphi(\widehat{e})]^{1-\beta}\right\}}, \\
\theta & =-1+\frac{\alpha(1+\rho)(1+n)[\varphi(\widehat{e})]^{1-\beta}}{\alpha(1+r)(1+\rho)[\varphi(\widehat{e})]^{-\beta}-\left\{(1+r)-(1+\rho)(1+n)[\varphi(\widehat{e})]^{1-\beta}\right\}} .
\end{aligned}
$$

In the first best, when $\widehat{k}$ is set at its optimal value, $(1+r)=(1+\rho)(1+n)[\varphi(\widehat{e})]^{1-\beta}$ 
and equation (60) simplifies to $i=0$; similarly equation (61) reduces to $\theta=-1+$ $(1+n) \varphi(\widehat{e}) /(1+r)=-1+[\varphi(\widehat{e})]^{\beta} /(1+\rho)<0$ which is the first-best value of $\theta$ derived in equation (56).

Observe also that $1+\theta$ must always be positive. It then follows that denominator on the right-hand side of (61) and thus (60) is positive. This implies that $i$ has the same sign as $(1+r)-(1+\rho)(1+n)[\varphi(\widehat{e})]^{1-\beta}$. Put differently, when second-best optimality requires $i>0$, it means that $1+r>(1+\rho)(1+n)[\varphi(\widehat{e})]^{1-\beta}$ and the equilibrium is characterized by a "low" physical-capital to human-capital ratio. On the other hand, when $i<0$ is optimal the equilibrium is characterized by a "high" physical-capital to human-capital ratio. This makes sense. A positive level of $i$ is associated with a "high" level of $\theta$ which depresses $\widehat{k}$. The following proposition summarizes the results of this section.

Proposition 5 (i) The second-best balanced growth environment wherein physical-capital cannot be controlled is characterized by equations (45) and (47).

(ii) Friedman rule does not hold in this environment.

(iii) The optimal nominal interest rate is given by equation (60) and the optimal monetary growth rate by (61).

(iv) A positive (negative) nominal interest rate is associated with a "low" ("high") value of physical-capital to human-capital ratio.

\section{Money, growth, and Friedman rule}

This section examines how the laissez-faire economy responds to changes in the rate of monetary growth. In doing so, it also determines the precise nature of the change in the second-best values of $\widehat{e}$ and $\widehat{k}$ discussed previously, as the inclusion of lump-sum taxes $\widehat{z}^{y}$ and $\widehat{z}^{o}$ in the steady-state equations does not change the results. It also revisits what one means in this model by "Friedman rule".

Substitute for $i$ from equation (29) into equations (25)-(26) and simplify to get 


$$
\begin{aligned}
& \frac{u_{d}(\widehat{c}, \widehat{d})}{u_{c}(\widehat{c}, \widehat{d})}=\frac{1}{1+r}\left(1-\frac{\alpha}{1+\theta}\right)+\frac{\alpha}{(1+n) \varphi(\widehat{e})}, \\
& \widehat{c}+\left[\frac{1-\alpha}{1+r}+\frac{\alpha}{(1+n) \varphi(\widehat{e})}\right] \widehat{d}=w-(1+r) \frac{\widehat{e}}{\varphi(\widehat{e})}
\end{aligned}
$$

With equations (31)-(32) determining $w$ and $r$ as functions of $\widehat{k}$, equations (62)-(63) determine $\widehat{c}$ and $\widehat{d}$ as functions of $\widehat{e}, \widehat{k}$ and $\theta$. Moreover, equation (30) relates $\widehat{e}$ to $w$ and $r$ and thus to $\widehat{k}$. Substituting for $\widehat{e}$ as a function $\widehat{k}$ in $(62)-(63)$ then yields a solution for $\widehat{c}$ and $\widehat{d}$ as functions of $\widehat{k}$ and $\theta$ only: $\widehat{c}(\widehat{k}, \theta)$ and $\widehat{d}(\widehat{k}, \theta)$. Now substitute $\widehat{c}(\widehat{k}, \theta)$ and $\widehat{d}(\widehat{k}, \theta)$ into equation $(27)$ and differentiate the resulting equation totally with respect to $\theta$. I show in the Appendix that the result is

$$
\frac{d \widehat{k}}{d \theta}=-\frac{1}{\Gamma}\left[\frac{\partial \widehat{c}}{\partial \theta}+\frac{\alpha}{(1+n) \varphi(\widehat{e})} \frac{\partial \widehat{d}}{\partial \theta}\right]
$$

where I also present the expression for $\Gamma$ noting that it is positive.

To determine the expression for the right-hand side of (64), partially differentiate the system of equations (62)-(63) with respect to $\theta$. Define

$$
\Delta \equiv\left(\widehat{u}_{c d}-\frac{\widehat{u}_{d}}{\widehat{u}_{c}} \widehat{u}_{c c}\right)\left[\frac{1-\alpha}{1+r}+\frac{\alpha}{(1+n) \varphi(\widehat{e})}\right]-\left(\widehat{u}_{d d}-\frac{\widehat{u}_{d}}{\widehat{u}_{c}} \widehat{u}_{c d}\right) .
$$

I prove in the Appendix that $\Delta>0$ and that

$$
\begin{aligned}
\frac{\partial \widehat{c}}{\partial \widehat{\theta}} & =\frac{1}{\Delta}\left[\frac{1-\alpha}{1+r}+\frac{\alpha}{(1+n) \varphi(\widehat{e})}\right] \frac{\alpha \widehat{u}_{c}}{(1+r)(1+\theta)^{2}}>0 \\
\frac{\partial \widehat{d}}{\partial \widehat{\theta}} & =\frac{1}{\Delta} \frac{-\alpha \widehat{u}_{c}}{(1+r)(1+\theta)^{2}}<0 .
\end{aligned}
$$

Intuitively, as $\theta$ increases the relative price of future goods to present consumption increases so that consumers respond by lowering their consumption of future goods and increasing their consumption of present goods. 
Substituting for $\partial \widehat{c} / \partial \theta$ and $\partial \widehat{d} / \partial \theta$ from (66)-(67) into the bracketed expression on the right-hand side of (64) yields

$$
\frac{\partial \widehat{c}}{\partial \theta}+\frac{\alpha}{(1+n) \varphi(\widehat{e})} \frac{\partial \widehat{d}}{\partial \theta}=\frac{1}{\Delta} \frac{\alpha(1-\alpha) \widehat{u}_{c}}{(1+r)^{2}(1+\theta)^{2}}>0 .
$$

Consequently,

$$
\frac{d \widehat{k}}{d \theta}<0
$$

This result may at first appear to be counter-intuitive. An increase in $\theta$ increases the cost of holding money. As a result, consumers should want to lower their cash holdings and switch into holdings of real capital. The intuition lies in the model's rationalization for holding money. With a Clower cash constraint, people's future consumption is equal to a multiple of their cash holdings. Thus a reduction in cash holdings implies a higher reduction in future consumption. This, in turn, requires a smaller level of real savings to be carried into the future.

Next, recall that $d \widehat{e} / d \theta=(d \widehat{e} / d \widehat{k})(d \widehat{k} / d \theta)$ with $d \widehat{e} / d \widehat{k}>0$ from (59). Consequently, $d \widehat{e} / d \theta<0$. Now with the growth rate of the economy being $g=\varphi(\widehat{e})-1$ and $\varphi^{\prime}(\widehat{e})>0, g$ moves positively with $\widehat{e}$ and

$$
\frac{d g}{d \theta}<0
$$

This result is summarized as:

Proposition 6 An increase in the money growth rate leads to a reduction in the balanced growth path values of the physical capital per human capital ratio and the rate of growth of the economy.

\subsection{Non-uniqueness of Friedman rule}

That Friedman rule of $i=0$ ensures the satisfaction of the optimality condition (45) is predicated on the stipulation that there are no consumption taxes in the economy. 
Assume instead that the government imposes a tax on the consumption of the young, $c$, at the rate of $\tau$. This changes the market equilibrium condition (25) to ${ }^{16}$

$$
\frac{u_{d}(\widehat{c}, \widehat{d})}{u_{c}(\widehat{c}, \widehat{d})}=\frac{1+\alpha i /(1+\theta)}{(1+\tau)(1+r)}
$$

This equation will be reduced to the optimality condition (45) as long as

$$
i=\frac{\tau(1+\theta)}{\alpha} \text {. }
$$

Moreover, one can easily see from (29) that to have (68) satisfied, all that is needed is to set $\theta$, for any given $\tau$, according to

$$
\theta=\frac{\alpha(1+n) \varphi(\widehat{e})}{\alpha(1+r)-\tau(1+n) \varphi(\widehat{e})}-1=\frac{\alpha}{\alpha(1+\rho)[\varphi(\widehat{e})]^{-\beta}-\tau}-1
$$

where $\widehat{e}$ takes its first-best value.

To sum, as long as there are no commodity taxes $(\tau=0), i$ must be equal to zero in the first best, requiring the monetary authority to set $\theta$ according to (56). However, if the fiscal authority levies a tax on the first-period consumption goods at a rate equal to $\tau$, monetary authority should set $\theta$ according to (69). Put differently, optimality condition (45) can be attained as a competitive equilibrium not just for $i=0$, and thus for a monetary growth rate governed by (56); but for a continuum of $i$ and a continuum of monetary growth rates and tax rates on $c$ that satisfy (69). That is, the Friedman requirement for a zero opportunity cost of money holding will be satisfied by a continuum

${ }^{16}$ Observe also that allowing for a tax rate on $c$ changes the market conditions $(52)-(53)$ to

$$
\begin{aligned}
(1+\tau) \widehat{c}+\left[1+\frac{\alpha(i-\theta)}{1+\theta}\right] \frac{\widehat{d}}{1+r} & =w-(1-\sigma)(1+r) \frac{\widehat{e}}{\varphi(\widehat{e})}-\widehat{z}^{y}-\frac{\widehat{z}^{o}}{1+r}, \\
(1+n)[\widehat{k} \varphi(\widehat{e})+\widehat{e}]+\frac{\alpha}{1+n} \frac{\widehat{d}}{\varphi(\widehat{e})} & =w-(1-\sigma)(1+r) \frac{\widehat{e}}{\varphi(\widehat{e})}-(1+\tau) \widehat{c}-\widehat{z}^{y} .
\end{aligned}
$$

It also changes the government's budget constraint (51) to

$$
(1+n)\left[\widehat{z}_{t}^{y}+\tau \widehat{c}_{t}-\sigma\left(1+r_{t}\right) \frac{\widehat{e}_{t}}{\varphi\left(\widehat{e}_{t}\right)}\right]+\frac{\widehat{z}_{t}^{o}}{\varphi\left(\widehat{e}_{t}\right)}=0 .
$$


of $(\tau, \theta)$. Intuitively, what is important here is the relative intertemporal price. In this model, the two policy instruments $\tau$ and $\theta$ control this single price (through $i$ ). In other words, we have one instrument too many. ${ }^{17}$

Proposition 7 Friedman rule can be satisfied by a continuum of monetary growth rates and tax rates on consumption during working years with the two being related according to equation (69) resulting in a nominal interest rate that is characterized by (68). Only if there are no taxes on consumption during working years, Friedman rule requires the nominal interest rate to be zero. In this case, the monetary growth rate is negative and given by equation (56).

\section{Conclusion}

This paper has studied the implications of introducing money into an overlappinggenerations model with endogenous growth where the rationalization for money holding comes from the Clower's cash-in-advance constraint. It has considered an economy populated with finitely-lived individuals whose human capital is determined partly through education and partly through their inherited human capital. Throughout the paper, to emphasize allocative efficiency, the paper has assumed no government tax requirements. With an external revenue requirement, one can always reject Friedman rule by suitably ruling out certain fiscal instruments. ${ }^{18}$

The main message of the paper has been that, as long as the government can fully control the level of physical capital in the economy and sets it to satisfy the modified golden rule, Friedman rule remains optimal. The result holds regardless of the ability of the government to control the level of human capital. With the control of human capital, controlling physical capital yields a first-best environment. Given this perspec-

\footnotetext{
${ }^{17}$ This does not arise in monetary models with money in the utility function. There, real balances also enter the utility function and the two instruments $\tau$ and $\theta$ are needed to control the relative intertemporal price and real balances.

${ }^{18}$ The stark example is provided by the case when there are no fiscal instruments.
} 
tive, the result has generalized the earlier result of Abel (1987) and Gahvari (1988) derived for overlapping-generations models without endogenous growth. Without the control of human capital, the economy is in a second-best environment. The result thus contradicts one's intuition based on the second-best theory. The paper has clarified this apparent contradiction by demonstrating that introducing an additional distortion in the economy, via the violation of Friedman rule, does nothing to alleviate the existing distortion in human capital accumulation as long as one can fully control physical capital accumulation. Furthermore, the paper has demonstrated that notwithstanding a zero nominal interest rate in both first- and second-best environments, the monetary growth rate and the economy's endogenous rate of growth are both smaller in the second best.

The paper has also studied another second-best environment; one in which human capital accumulation can be controlled but not physical capital. It has shown that in this setting the distortion due to the violation of Friedman rule does alleviate the distortion due to the lack of physical capital accumulation. Here, second-best optimality calls for the violation of Friedman rule.

Another interesting result is the existence of a negative relationship between money growth rate on the one hand and the endogenous growth rate of the economy on the other. The reason for this is that, in a cash-in-advance constraint model, people carry cash to finance a fraction of their future consumption. Put the other way, their future consumption is equal to a multiple of their cash holdings. Consequently, an increase in the growth rate of money supply, which increases the cost of holding cash and reduces money holdings, leads to a reduction in future consumption that is higher than the original reduction in the individuals' money holdings. This, in turn, requires a smaller level of real savings to be carried into the future. Finally, the paper has also shown that, in the context of a cash-in-advance constraint model, Friedman rule is not unique. A continuum of monetary growth rates and tax rates on consumption during working years result in a zero opportunity cost of holding money. 


\section{Appendix}

\section{Per human capital notation used in the paper:}

$$
\widehat{e}_{t} \equiv e_{t} / h_{t-1}, \widehat{k}_{t}=k_{t} / h_{t}, \widehat{c}_{t} \equiv c_{t} / h_{t}, \widehat{d}_{t} \equiv d_{t} / h_{t-1}, \varphi\left(\widehat{e}_{t}\right) \equiv h_{t} / h_{t-1}
$$

A useful property: Rewrite equation (47) as

$$
[w-(1+n) \widehat{e}] \varphi^{\prime}(\widehat{e})=(1+n)[\varphi(\widehat{e})]^{1-\beta}\left[(1+\rho)-[\varphi(\widehat{e})]^{\beta}\right]
$$

Then transversality condition $(46)[\varphi(\widehat{e})]^{\beta}<1+\rho$ also implies that

$$
w-(1+n) \widehat{e}>0 .
$$

Derivation of (64): Substitute $\widehat{c}(\widehat{k}, \theta)$ and $\widehat{d}(\widehat{k}, \theta)$, the solution found from equations (62)-(63), into equation (27) to get

$$
\begin{aligned}
& (1+n)[\widehat{k} \varphi(\widehat{e}(\widehat{k}))+\widehat{e}(\widehat{k})]+\frac{\alpha}{1+n} \frac{\widehat{d}(\widehat{k}, \theta)}{\varphi(\widehat{e}(\widehat{k}))}= \\
& w-(1+r) \frac{\widehat{e}(\widehat{k})}{\varphi(\widehat{e}(\widehat{k}))}-\widehat{c}(\widehat{k}, \theta) .
\end{aligned}
$$

Move the expressions on the right-hand side of (A2) to its left-hand side and let

$$
\begin{aligned}
\Theta(\widehat{k}, \theta) \equiv & (1+n)[\widehat{k} \varphi(\widehat{e}(\widehat{k}))+\widehat{e}(\widehat{k})]+\frac{\alpha}{1+n} \frac{\widehat{d}(\widehat{k}, \theta)}{\varphi(\widehat{e}(\widehat{k}))} \\
& -w+(1+r)(1+r) \frac{\widehat{e}(\widehat{k})}{\varphi(\widehat{e}(\widehat{k}))}+\widehat{c}(\widehat{k}, \theta) .
\end{aligned}
$$

Differentiating $\Theta(\widehat{k}, \theta)=0$ totally with respect to $\theta$ yields

$$
\frac{\partial \Theta(\widehat{k}, \theta)}{\partial \theta}+\frac{\partial \Theta(\widehat{k}, \theta)}{\partial \widehat{k}} \frac{d \widehat{k}}{d \theta}=-\left[\frac{\partial \widehat{c}(\widehat{k}, \theta)}{\partial \theta}+\frac{\alpha}{1+n} \frac{1}{\varphi(\widehat{e})} \frac{\partial \widehat{d}(\widehat{k}, \theta)}{\partial \theta}\right]
$$


Rearranging and defining $\Gamma \equiv \partial \Theta(\widehat{k}, \theta) / \partial \widehat{k}$ yields equation (64) in the text.

Now observe that one can think of the left-hand side of (A2) as the demand for $\widehat{k}$ and its right-hand side as the supply of $\widehat{k}$. The static stability condition then requires that the excess demand function $\Theta(\widehat{k}, \theta)$ to be downward-sloping in $r$ or upward-sloping in $\widehat{k}$. Consequently, $\Gamma=\partial \Theta(\widehat{k}, \theta) / \partial \widehat{k}>0$.

Derivation of (66)-(67): Differentiate equations (62)-(63) partially with respect to $\theta$. The resulting equations are, in matrix notation,

$$
\left(\begin{array}{cc}
\widehat{u}_{c d}-\frac{\widehat{u}_{d}}{\widehat{u}_{c}} \widehat{u}_{c c} & \widehat{u}_{d d}-\frac{\widehat{u}_{d}}{\widehat{u}_{c}} \widehat{u}_{c d} \\
1 & \frac{1-\alpha}{1+r}+\frac{\alpha}{(1+n) \varphi(\widehat{e})}
\end{array}\right)\left(\begin{array}{c}
\frac{\partial \widehat{c}}{\partial \theta} \\
\frac{\partial \hat{d}}{\partial \theta}
\end{array}\right)=\left(\begin{array}{c}
\frac{\alpha \widehat{u}_{c}}{(1+r)(1+\theta)^{2}} \\
0
\end{array}\right) .
$$

Pre-multiplying (A3) by the inverse of the $2 \times 2$ matrix that appears in its left-hand side yields

$$
\left(\begin{array}{c}
\frac{\partial \widehat{c}}{\partial \theta} \\
\frac{\partial \widehat{d}}{\partial \theta}
\end{array}\right)=\frac{1}{\Delta}\left(\begin{array}{cc}
\frac{1-\alpha}{1+r}+\frac{\alpha}{(1+n) \varphi(\widehat{e})} & -\widehat{u}_{d d}+\frac{\widehat{u}_{d}}{\widehat{u}_{c}} \widehat{u}_{c d} \\
-1 & \widehat{u}_{c d}-\widehat{u}_{c c} \widehat{u}_{d}
\end{array}\right)\left(\begin{array}{c}
\frac{\alpha \widehat{u}_{c}}{(1+r)(1+\theta)^{2}} \\
0
\end{array}\right),
$$

where $\Delta$ is defined in the text by equation (65). Equations (66)-(67) allow immediately from (A4).

Proof of $\Delta>0$ : To determine the sign of $\Delta$, rewrite its expression from (65) as

$$
\begin{aligned}
\Delta & =-\left[\frac{1-\alpha}{1+r}+\frac{\alpha}{(1+n) \varphi(\widehat{e})}\right] \frac{\widehat{u}_{d}}{\widehat{u}_{c}} \widehat{u}_{c c}-\widehat{u}_{d d}+\left[\frac{1-\alpha}{1+r}+\frac{\alpha}{(1+n) \varphi(\widehat{e})}+\frac{\widehat{u}_{d}}{\widehat{u}_{c}}\right] \widehat{u}_{c d} \\
& =\left[\frac{1-\alpha}{1+r}+\frac{\alpha}{(1+n) \varphi(\widehat{e})}\right]\left(\widehat{u}_{c d}-\frac{\widehat{u}_{d}}{\widehat{u}_{c}} \widehat{u}_{c c}\right)+\left(\frac{\widehat{u}_{d}}{\widehat{u}_{c}} \widehat{u}_{c d}-\widehat{u}_{d d}\right) .
\end{aligned}
$$

Assuming $d$ and $c$ are normal goods, one can easily show that $\widehat{u}_{c d}-\left(\widehat{u}_{d} / \widehat{u}_{c}\right) \widehat{u}_{c c}>0$ and $\left(\widehat{u}_{d} / \widehat{u}_{c}\right) \widehat{u}_{c d}-\widehat{u}_{d d}>0$ (where due to quasi-concavity of preferences, $-\left(\widehat{u}_{d} / \widehat{u}_{c}\right)^{2} \widehat{u}_{c c}-$ $\left.\widehat{u}_{d d}+2\left(\widehat{u}_{d} / \widehat{u}_{c}\right) \widehat{u}_{c d}>0\right)$. Consequently, $\Delta>0$. 


\section{References}

[1] Abel, A., 1987. Optimal monetary growth. Journal of Monetary Economics 19, 437-450.

[2] Atkinson, A., Sandmo, A., 1980. Welfare implications of the taxation of savings. Economic Journal 90, 529-549.

[3] Bhattacharya, J., Haslag, J., Martin, A., 2008. Optimal monetary policy and economic growth. European Economic Review, forthcoming.

[4] Bhattacharya, J., Haslag, J., Russell, S., 2005. The role of money in two alternative models: When is the Friedman rule optimal and why? Journal of Monetary Economics 52, 1401-1433.

[5] Chang, W.Y., Lai, C.C., 2000. Anticipated inflation in a monetary economy with endogenous growth. Economica 67, 399-417.

[6] Chang, J.J., Chang, W.Y., Lai, C.C., Wang, P., 2007. Equilibrium dynamics in an endogenous growth model of money and banking. Journal of Money, Credit, and Banking 39 (7), 1683-1710.

[7] Crettez, B., Michel, P., Wigniolle, B., 1999. Cash-in-advance constraints in the Diamond overlapping generations model: neutrality and optimality of monetary policies. Oxford Economic Papers 51, 431-452.

[8] Crettez, B., Michel, P., Wigniolle, B., 2002. Optimal monetary policy, taxes, and public debt in an intertemporal equilibrium. Journal of Public Economic Theory 4, 299-316.

[9] Diamond, P., 1965. National debt in a neoclassical growth model. American Economic Review 55, 1126-1150.

[10] Docquier, F., Paddison, O., Pestieau, P., 2007. Optimal accumulation in an endogenous growth setting with human capital. Journal of Economic Theory 134 (1), $361-378$.

[11] Dotsey, M., Sarte, P.D.G., 2000. Inflation uncertainty and growth in a cash-inadvance economy. Journal of Monetary Economics 45, 631-55.

[12] Freeman, S., 1993. Resolving differences over the optimal quantity of money. Journal of Money, Credit, and Banking 25 (4), 801-811.

[13] Friedman, M., 1969. The optimum quantity of money. In: Friedman, M., The Optimum Quantity of Money and Other Essays. Aldine Publishing Company, Chicago.

[14] Gahvari, F., 1988. Lump-sum taxation and the superneutrality and optimum quantity of money in life cycle growth models. Journal of Public Economics 36, 339-367. 
[15] Gahvari, F., 2007. The Friedman rule: old and new. Journal of Monetary Economics $54(2), 581-589$.

[16] Gomme, P., 1993. Money and growth revisited. Journal of Monetary Economics $32,51-77$.

[17] Hahn, F., Solow, R., 1995. A Critical Essay on Modern Macroeconomic Theory. Basil Blackwell, Oxford.

[18] Ireland, P.N., 2005. The liquidity trap, the real-balance effect and the Friedman rule. International Economic Review 46, 1271-1301.

[19] Jones, L.E., Manuelli, R.E., 1995. Growth and the effects of inflation. Journal of Economic Dynamics and Control 19, 1405-28.

[20] King, M., 1980. Savings and taxation. In Hughes, G., Heal, G. (Eds.), Public Policy and the Tax System. London: George Allen Unwin, 1-36.

[21] Lipsey, R.G., Lancaster, K., 1956. The general theory of second best. The Review of Economic Studies 24 (1), 11-32.

[22] Michel, P., Wigniolle, B., 2005. Cash-in-advance constraints, bubbles, and monetary policy. Macroeconomic Dynamics 9, 28-56.

[23] Paal, B., Smith, B.D., 2000. The sub-optimality of the Friedman rule and the optimum quantity of money. Manuscript.

[24] Phelps, E.S., 1973. Inflation in the theory of public finance. Swedish Journal of Economics 75(1), 67-82.

[25] Smith, B.D., 1991. Interest on reserves and sunspot equilibria: Friedman's proposal reconsidered. Review of Economic Studies 58, 93-105.

[26] Smith, B.D., 2002. Monetary policy, banking crises, and the Friedman rule. AEA Papers and Proceedings 92, 128-134.

[27] van der Ploeg, F., Alogoskoufis, G.S., 1994. Money and endogenous growth. Journal of Money, Credit, and Banking 26 (4), 771-791.

[28] Wang, P., Yip, C.K., 1992. Examining the long-run effect of money on economic growth. Journal of Macroeconomics 14, 359-69.

[29] Weil, P.,1989. Overlapping families of infinitely lived agents. Journal of Public Economics 38, 183-198.

[30] Weiss, L., 1980. The effects of money supply on economic welfare in the steady state. Econometrica 48 (3), 565-576. 


\section{CESifo Working Paper Series}

for full list see www.cesifo-group.org/wp

(address: Poschingerstr. 5, 81679 Munich, Germany, office@cesifo.de)

2645 Dominique Demougin, Oliver Fabel and Christian Thomann, Implicit vs. Explicit Incentives: Theory and a Case Study, May 2009

2646 Francesco C. Billari and Vincenzo Galasso, What Explains Fertility? Evidence from Italian Pension Reforms, May 2009

2647 Kjell Arne Brekke, Karen Evelyn Hauge, Jo Thori Lind and Karine Nyborg, Playing with the Good Guys - A Public Good Game with Endogenous Group Formation, May 2009

2648 Guglielmo Maria Caporale and Luis A. Gil-Alana, Multi-Factor Gegenbauer Processes and European Inflation Rates, May 2009

2649 Henning Bohn, A Static Model for Voting on Social Security, May 2009

2650 Markus Haavio and Kaisa Kotakorpi, The Political Economy of Sin Taxes, May 2009

2651 Augusto de la Torre, María Soledad Martínez Pería and Sergio L. Schmukler, Drivers and Obstacles to Banking SMEs: The Role of Competition and the Institutional Framework, May 2009

2652 Tobias Lindhe and Jan Södersten, Dividend Taxation, Share Repurchases and the Equity Trap, May 2009

2653 Assaf Razin and Edith Sand, Migration-Regime Liberalization and Social Security: Political-Economy Effect, May 2009

2654 Yin-Wong Cheung and Hiro Ito, A Cross-Country Empirical Analysis of International Reserves, May 2009

2655 Bart Cockx and Bruno Van der Linden, Flexicurity in Belgium. A Proposal Based on Economic Principles, May 2009

2656 Michael Melvin, Lukas Menkhoff and Maik Schmeling, Exchange Rate Management in Emerging Markets: Intervention via an Electronic Limit Order Book, May 2009

2657 Susanne Neckermann, Reto Cueni and Bruno S. Frey, What is an Award Worth? An Econometric Assessment of the Impact of Awards on Employee Performance, May 2009

2658 Steven Brakman, Harry Garretsen and Charles van Marrewijk, Economic Geography within and between European Nations: The Role of Market Potential and Density across Space and Time, May 2009 
2659 Giovanni Facchini and Cecilia Testa, Reforming Legislatures: Is one House better than two?, May 2009

2660 Carsten Kowalczyk and Raymond Riezman, Trade Agreements, May 2009

2661 Oliver Falck, Stephan Heblich and Elke Luedemann, Identity and Entrepreneurship, May 2009

2662 Christian Lessmann and Gunther Markwardt, One Size Fits All? Decentralization, Corruption, and the Monitoring of Bureaucrats, May 2009

2663 Felix Bierbrauer, On the Legitimacy of Coercion for the Financing of Public Goods, May 2009

2664 Alessandro Cigno, Agency in Family Policy: A Survey, May 2009

2665 Claudia M. Buch and Christian Pierdzioch, Low Skill but High Volatility?, May 2009

2666 Hendrik Jürges, Kerstin Schneider, Martin Senkbeil and Claus H. Carstensen, Assessment Drives Learning: The Effect of Central Exit Exams on Curricular Knowledge and Mathematical Literacy, June 2009

2667 Eric A. Hanushek and Ludger Woessmann, Schooling, Cognitive Skills, and the Latin American Growth Puzzle, June 2009

2668 Ourania Karakosta, Christos Kotsogiannis and Miguel-Angel Lopez-Garcia, Does Indirect Tax Harmonization Deliver Pareto Improvements in the Presence of Global Public Goods?, June 2009

2669 Aleksandra Riedl and Silvia Rocha-Akis, Testing the Tax Competition Theory: How Elastic are National Tax Bases in OECD Countries?, June 2009

2670 Dominique Demougin and Carsten Helm, Incentive Contracts and Efficient Unemployment Benefits, June 2009

2671 Guglielmo Maria Caporale and Luis A. Gil-Alana, Long Memory in US Real Output per Capita, June 2009

2672 Jim Malley and Ulrich Woitek, Productivity Shocks and Aggregate Cycles in an Estimated Endogenous Growth Model, June 2009

2673 Vivek Ghosal, Business Strategy and Firm Reorganization under Changing Market Conditions, June 2009

2674 Francesco Menoncin and Paolo M. Panteghini, Retrospective Capital Gains Taxation in the Real World, June 2009

2675 Thomas Hemmelgarn and Gaëtan Nicodème, Tax Co-ordination in Europe: Assessing the First Years of the EU-Savings Taxation Directive, June 2009 
2676 Oliver Himmler, The Effects of School Competition on Academic Achievement and Grading Standards, June 2009

2677 Rolf Golombek and Michael Hoel, International Cooperation on Climate-Friendly Technologies, June 2009

2678 Martin Cave and Matthew Corkery, Regulation and Barriers to Trade in Telecommunications Services in the European Union, June 2009

2679 Costas Arkolakis, A Unified Theory of Firm Selection and Growth, June 2009

2680 Michelle R. Garfinkel, Stergios Skaperdas and Constantinos Syropoulos, International Trade and Transnational Insecurity: How Comparative Advantage and Power are Jointly Determined, June 2009

2681 Marcelo Resende, Capital Structure and Regulation in U.S. Local Telephony: An Exploratory Econometric Study; June 2009

2682 Marc Gronwald and Janina Ketterer, Evaluating Emission Trading as a Policy Tool Evidence from Conditional Jump Models, June 2009

2683 Stephan O. Hornig, Horst Rottmann and Rüdiger Wapler, Information Asymmetry, Education Signals and the Case of Ethnic and Native Germans, June 2009

2684 Benoit Dostie and Rajshri Jayaraman, The Effect of Adversity on Process Innovations and Managerial Incentives, June 2009

2685 Peter Egger, Christian Keuschnigg and Hannes Winner, Incorporation and Taxation: Theory and Firm-level Evidence, June 2009

2686 Chrysovalantou Milliou and Emmanuel Petrakis, Timing of Technology Adoption and Product Market Competition, June 2009

2687 Hans Degryse, Frank de Jong and Jérémie Lefebvre, An Empirical Analysis of Legal Insider Trading in the Netherlands, June 2009

2688 Subhasish M. Chowdhury, Dan Kovenock and Roman M. Sheremeta, An Experimental Investigation of Colonel Blotto Games, June 2009

2689 Alexander Chudik, M. Hashem Pesaran and Elisa Tosetti, Weak and Strong Cross Section Dependence and Estimation of Large Panels, June 2009

2690 Mohamed El Hedi Arouri and Christophe Rault, On the Influence of Oil Prices on Stock Markets: Evidence from Panel Analysis in GCC Countries, June 2009

2691 Lars P. Feld and Christoph A. Schaltegger, Political Stability and Fiscal Policy - Time Series Evidence for the Swiss Federal Level since 1849, June 2009

2692 Michael Funke and Marc Gronwald, A Convex Hull Approach to Counterfactual Analysis of Trade Openness and Growth, June 2009 
2693 Patricia Funk and Christina Gathmann, Does Direct Democracy Reduce the Size of Government? New Evidence from Historical Data, 1890-2000, June 2009

2694 Kirsten Wandschneider and Nikolaus Wolf, Shooting on a Moving Target: Explaining European Bank Rates during the Interwar Period, June 2009

2695 J. Atsu Amegashie, Third-Party Intervention in Conflicts and the Indirect Samaritan's Dilemma, June 2009

2696 Enrico Spolaore and Romain Wacziarg, War and Relatedness, June 2009

2697 Steven Brakman, Charles van Marrewijk and Arjen van Witteloostuijn, Market Liberalization in the European Natural Gas Market - the Importance of Capacity Constraints and Efficiency Differences, July 2009

2698 Huifang Tian, John Whalley and Yuezhou Cai, Trade Sanctions, Financial Transfers and BRIC's Participation in Global Climate Change Negotiations, July 2009

2699 Axel Dreher and Justina A. V. Fischer, Government Decentralization as a Disincentive for Transnational Terror? An Empirical Analysis, July 2009

2700 Balázs Égert, Tomasz Koźluk and Douglas Sutherland, Infrastructure and Growth: Empirical Evidence, July 2009

2701 Felix Bierbrauer, Optimal Income Taxation and Public Goods Provision in a Large Economy with Aggregate Uncertainty, July 2009

2702 Marc Gronwald, Investigating the U.S. Oil-Macroeconomy Nexus using Rolling Impulse Responses, July 2009

2703 Ali Bayar and Bram Smeets, Government Deficits in the European Union: An Analysis of Entry and Exit Dynamics, July 2009

2704 Stergios Skaperdas, The Costs of Organized Violence: A Review of the Evidence, July 2009

2705 António Afonso and Christophe Rault, Spend-and-tax: A Panel Data Investigation for the EU, July 2009

2706 Bruno S. Frey, Punishment - and beyond, July 2009

2707 Michael Melvin and Mark P. Taylor, The Crisis in the Foreign Exchange Market, July 2009

2708 Firouz Gahvari, Friedman Rule in a Model with Endogenous Growth and Cash-inadvance Constraint, July 2009 